\title{
Investigating memory storage difficulties in Multiple Sclerosis
}

Theofilidis Antonis

Occupational Therapy Department University of Western Makedonia - Greece

Corresponding Author: Theofilidis Antonis, Occupational Therapy Department University of Western Makedonia - Greece

Received date: July 08, 2021; Accepted date: July 23, 2021; Published date: July 29,2021

Citation: Theofilidis Antonis (2021) Investigating memory storage difficulties in Multiple Sclerosis. J. Neuroscience and Neurological Surgery. 9(5); DOI:10.31579/2578-8868/185

Copyright: (C) 2021 Theofilidis Antonis, This is an open-access article distributed under the terms of The Creative Commons Attribution License, which permits unrestricted use, distribution, and reproduction in any medium, provided the original author and source are credited

\begin{abstract}
:
Memory by itself as a function, loses its capabilities with a normal deterioration. However, there are acquired conditions that negatively affect the functions of memory, resulting in dysfunction of its stages. Thus possible damage to the structures of the hemisphere that controls these processes disrupts the comprehension, organization and categorization of the material to be memorized. Patients with damage to these systems will have difficulty remembering because they have not adequately coded the material.

Patients with Multiple Sclerosis report short-term memory difficulties in the sense that they have difficulty remembering details of recent conversations and events.

Aim: To investigate the memory storage difficulties in Multiple Sclerosis.

Materials and Methods: An international literature review was performed on Memory Disorders in Multiple Sclerosis

Conclusion: In patients with Multiple Sclerosis learning deficits are greatly aided by processing speed and working memory. It has been observed that slow mental processing makes it difficult for many patients with Multiple Sclerosis to capture an entire verbal message, especially if it is large, complex, delivered quickly and with external stimuli, such as a noisy environment.
\end{abstract}

Keywords: memory difficulties; multiple sclerosis

\section{Introduction}

The structures of the brain, the hippocampus and the bilateral structures of the middle temporal lobes contribute to the storage process. Damage to these structures presents storage difficulties. People with such defects can properly analyze the information, (make successful coding, but are not able to keep it in storage). Long-term memory is deficient and information retention deteriorates upon exposure. These patients have a pathologically rapid expiration rate (Theofilidis, 2020).

Diagnoses for patients with middle temporal lobe syndrome include anoxia-induced brain damage, herpetic encephalitis, and early-onset Alzheimer's disease. Also, people who have undergone electroconvulsive therapy may have transient restraint problems.

The recovery stage is associated with the contribution of the frontal lobe to memory capacity. These structures are involved in creating strategies, in memory for the timeline, in self-monitoring, and in initiating recovery. Therefore, people with craniocerebral injuries to these structures have changes in their ability to retrieve stored information effectively. It is prone to specific mnemonic errors, as well as distortion and fiction errors. They may also have poor memory of the source and confuse the source of their own learning. They can recall facts, but not the time frame in which the information was obtained (Theofilidis,
2020).Thus, the type of memory loss depends on the nature of the injury, the degree and location of the injury (Sohlberg \& Mateer, 2001).

\section{Forgetfulness}

Normal forgetfulness is the loss or limited access to information that may have been recently stored as well as to information that has been stored in the past. The rate of normal forgetfulness depends on and varies depending on psychological parameters such as the personal importance of the mnemonic material, the fundamental style, depending on the age differences and possibly with some developmental differences. Normal forgetfulness is different from amnesia. Amnesia involves a person's inability to access or even record much of his or her personal memories.

What processes are responsible for normal forgetfulness is not yet clear. The Freudian view supports the hypothesis that nothing is lost from memory and that the problem lies in defective or repressed recovery processes. Perhaps the most important of these processes, as Bower (2000) argues, is autonomic degeneration due to physiological and metabolic processes with progressive erosion of synaptic connections. As Fuster (1995) also notes that the initial fixation of memory is responsible for some cases of forgetfulness. This becomes apparent in clinical cases in which the processes of attention are so disturbed that transient stimuli, during discussion or as events, receive almost no attention and are stored 
incompletely or not stored at all (Lezak, 2009).

\section{Memory disorders -Amnesia}

When the recording or storage processes are disrupted by an illness or accident, retrieving new information or retrieving old information can range from elementary to non-existent. The nature of these deficits is largely determined by the location of the damage, as memory impairment can be the result of damage to different parts of the brain. A transient disturbance of these processes, often occurring in a craniocerebral injury or electroconvulsive therapy for psychiatric conditions, impairs memory for the period of the disorder. Complete loss of these abilities leads to a complete memory gap from the onset of the disorder (Theofilidis, 2020).

\section{Frontal amnesia}

Frontal amnesia is the inability or impaired ability of a person to remember the events of his life, which begins at the onset of the disease. People with frontal amnesia are unable to learn and have recent memory impairment. The type and severity of the memory defect vary somewhat depending on the nature of the disorder.

\section{Retrograde amnesia}

Retrograde amnesia is the loss of memory for events that preceded the onset of brain damage. When retrograde amnesia occurs in the context of brain disease, the loss of a person's personal history and life events can go back many years or even decades, and is usually followed by a time gradient in which newer memories are more prone to loss. . In many cases, retrograde memory loss, often referred to as retrograde amnesia, is temporary. Memories of life events gradually return to a period just before the event that caused the brain damage. This is widely known as declining retrospective amnesia. A small retrospective amnesia for events that immediately preceded a brain injury is common. People usually do not remember events immediately before or during the accident, because this information remained in the short-term memory and did not manage to be consolidated in the long-term memory.

Permanent long-term retrograde amnesia is rare and occurs only with some degree of precursor memory loss. In general, retrograde amnesia affects episodic memory and semantic memory to varying degrees.

In some patients with frontal lobe damage, retrograde amnesia can cause a problem with the timing and memory of the source, despite actual loss of distant memory.

The distinction for retrograde amnesia lies in the fact that the anatomical structures involved in new learning and the recall of old memories are different. Hippocampal damage is implicated in defective storage processes of frontal amnesia.

\section{Recurrent amnesia}

Recurrence problems have been associated with intercerebral lesions, more specifically in nuclei in the mastia and / or in the ventricle and interconnects, and also with other subcortical structures or cortical areas (Lezak, 2009). Multiplicative memory is another example of an isolated neurological disorder (rather than a loss) of memory, which usually results in damage to the frontal lobes. It is a case in which a person believes that there is a duplicate of a familiar part or person. Neuropsychological analyzes (Kapur, 1993; Schmidtke \& Vollmer, 1997) of cases of proliferative memory suggest that it represents a combination of perceptual and memory deficits, as well as deficient ability in information synthesis. Conditions such as retrograde amnesia and proliferative memory remind clinicians that memory is not a single function but is part of a highly synthetic cognitive system (Sohlberg \& Mateer, 2004).

\section{Post-traumatic amnesia}

Post-traumatic amnesia is a special type of precursor amnesia in which a person cannot remember events in the order in which they occurred. It is the period of confusion or disorientation that occurs after the comatose stage and is characterized by the inability to store or retrieve information, as they evolve from day to day or from minute to minute. The duration of post-traumatic amnesia is probably a better prognostic indicator than the duration of coma (Levi, Benton \& Grossman, 1982). However, measuring the duration of post-traumatic amnesia is not easy. Studies (Ahmed, Bierley, Sheikh, \& Date, 2000) differ in how they determine when post-traumatic amnesia begins and whether it is measured prospectively or retrospectively. Most medical centers with rehabilitation services now attempt to record the duration of PostTraumatic Amnesia using a weighted method. The Galveston Orientation and Amnesia Test, the Amnesia Image Test, and the Westmead Scales are used early in the onset of memory deficits (Sohlberg \& Mateer, 2004).

\section{Specific memory loss}

Memory loss can be specific to verbal or non-verbal material. Many memory tests assess memory loss by comparing performance to verbal and non-verbal memory tests. This distinction implies that memory for speech-based information (letters, words, names, paragraphs) is encoded and stored separately from information that is not easily characterized verbally (abstract designs, shapes, melodies, faces, places in space). People with focal deficits are more likely to have material-specific deficits than people with diffuse involvement. For example, damage to the left temporal lobe results in memory impairment for words, while damage to the right temporal lobe is more likely to result in memory impairment for visual information (Milner, 1970).

Due to the design of many of the memory tests, the diagnosis of materialspecific memory deficits may be overemphasized. It often happens that the different performances in verbal and nonverbal memory measurement tools reflect differences in the patient's underlying ability to analyze verbal versus nonverbal information, previously described as a coding deficit. However, special care is needed in formulating assumptions about how patients encode, process, or analyze information presented to them. For example, a patient may verbally encode a visual representation (e.g., call an abstract design "cobweb") (Theofilidis, 2020).

If, however, a patient shows particular difficulty in learning and retrieving specific verbal or non-verbal information, this information will greatly influence the direction of treatment (Sohlberg \& Mateer, 2004).

\section{Daily memory}

The goal of all rehabilitation programs is to improve the daily functioning of people suffering from cognitive impairment. This has encouraged the expansion of memory models to incorporate aspects of everyday memory. The most practical aspect of everyday memory is that of perspective memory. It is the ability that allows the person to remember to carry out his intentions. Examples of perspective memory are remembering the person taking their medication, as well as calling someone. Perspective memory performance is more closely linked to a person's daily functioning than to traditional recall tests (Brandimonte, Einstein, \& McDaniel, 1996).

Dobbs and Reeves (1996) clarify the cognitive functions associated with perspective memory and emphasize that perspective memory is not a kind of memory work but a set of processes. Describe the following interactive components that are responsible: a) metacognition, knowledge of the particular project undertaken, b) design, formulation of steps to facilitate performance, c) monitoring, periodic reminder that the project must be executed and intervals evaluation of relevant conditions, d) recall of the 
content, recall of the intended action and monitoring of six, e) recollection of whether the operation has taken place.

Another aspect of everyday memory is that of post-memory or individuals' understanding of their own memory function. People are aware of their own strengths and weaknesses in relation to memory and learning and this awareness affects their behavior. Some people with memory problems have deficient memory and are unable to recognize the magnitude or even the nature of the memory impairment. They may not have a sense of what actions would be helpful to alleviate their memory problems and may bring about changes in the sense that they know (Sohlberg \& Mateer, 2004).

\section{Memory Disorders in Multiple Sclerosis}

Patients with Multiple Sclerosis report short-term memory difficulties in the sense that they have difficulty remembering details of recent conversations and events. But they do not have difficulty remembering events from the distant past. Semantic memory is often quite well preserved, but it has been observed, at times insufficient recall of distant learned events especially in tests that evaluate memory for famous people, events, and even autobiographical memory estimates for personal events. Recall to learning tests with multiple tests is usually disrupted. That is, patients often try in the first trial to retain all the material presented, finding their treatment crushed. They do much better in the next tests in which they are allowed to learn the list in slow increments. The reality is that patients fail to perform future actions due to the inadequacy in the initial consolidation of information given to them quickly and only once, as in normal conversation, give and take, but which is opposed to the failure of prospective memory alone.

Multiple Sclerosis Memory Disorder begins to acquire a frontal quality with deficits that are more pronounced in free recall tests due to inadequate coding and recovery. Consolidation is relatively unaffected. As a result, free recall is poorer than recall after irritation, but in the course of the disease it becomes inferior to reading. Based on the above, the conclusion is reached (Rao, Leo, \& St Aubin-Faubert 1989. Rao, Grafman, DiGiulio, et al., 1993) that in PS the recall is preferably stopped while the processes of codification and consolidation are maintained.

However, patients' ability to activate new strategies is impaired, for example, they are less likely to use semantic grouping and visual imagery. This contributes to insufficient coding in the first test in learning activities with a series of tests and in learning tests of combinations with poor stimulus-target correlations. They are also less consistent in retrieving objects from one learning test to the next, resulting in forgetting material faster than healthy individuals. Intangible memory is always intact as evidenced by tests of perceptual-motor skills, such as moving the target, serial visual reaction time, and reading in the mirror (Beatty, Goodkin, Monson, \& Beatty, 1990. Rao, Grafman, DiGiulio, et al, 1993).

Learning deficits are greatly aided by processing speed and working memory. It has been observed that slow mental processing makes it difficult for many patients to capture an entire verbal message, especially if it is large, complex, delivered quickly and with external stimuli, such as a noisy environment (Howiesen \& Lezak, 2002). Thus a lot of information, which passes very quickly in daily life and which very easily healthy people can receive, is usually lost by these patients (Lezak, 2009).

\section{Bibliography}

1. Ahmed, S., Bierley, R., Sheikh, J.I., \& Date, E. S. (2000). Post-traumatic amnesia after closed head injury: A review of the literature and some suggestions for further research. Brain Injury, 14(9),765-780.

2. Beatty,W.W., Goodkin, D.E., Hertsgaard, D., \& Monson, N. (1990). Clinical and demographic predictors of cognitive performance in multiple sclerosis. Archires of Neurology, 47, 305-308.

3. Brandimonte, M., Einstein, G. O., \& McDaniel, M. A. (Eds.). (1996). Prospective memory: Theory and applications. Mahwah, NJ: Erlbaum.

4. Dobbs, A. R., \& Reeves, B. M. (1996). Prospective memory: More than memory. In Brandimonte, G. O. Einstein, \& M. A. McDaniel (Eds.), Prospective memory:Theory and applications, 199-226. Mahwah, NJ: Erlbaum.

5. Fuster, J.M. (1995). Memory in the cerebral cortex: An empirical approach to neural networks in the human and nonhuman primate. Cambridge, MA: MIT Press.

6. Howieson, D.B \& Lezak, M.D. (2002b). Separating memory from other cognitive problems. In A. Baddeley (Eds.), Handbook of memory disorders (2nd ed.).Chichester, UK: Wiley

7. Kapur, N. (1993). Focal retrograde amnesia in neurological disease: A critical review.Cortex, 29, 217-234.

8. Levin, H. S., Benton, A. L., \& Grossman, R. G. (1982). Neurobehavioral consequences of closed head injury. New York: Oxford University Press.

9. Lezak, M.D. (2009). Neuropsychological assessment (3rd ed.). New York: Oxford University Press.

10. Milner, B. (1970). Memory and the medial temporal regions of the brain. In K. J. Pribram \& D. E. Broadbent (Eds.), Biological bases of memory (pp. 29- 50). New York: Academic Press.

11. Rao, S.M.,Leo, G.J., \& Aubin- Faubert, P. (1989). On the nature of memory disturbance in multiple sclerosis.Journal of Clinical and Experimental Neuropsychology, 11, 699-712.

12. Rao, S.M., Grafman, J., DiGiulio, D., et al. (1993). Memory dysfunction in multiple sclerosis: Its relation to working memory, semantic encoding and implicit learming. Neuropsychology, 7, 364-374.

13. Schmidtke, K., \& Vollmer, H. (1997). Retrograde amnesia: A study of its relation to anterograde amnesia and semantic memory deficits. Neuropsychologia, 35(4), 505-518.

14. Sohlberg, M.M. \& Mateer, C.A. (2001). Cognitive rehabilitation.An integrative neuropsychological approach. New York: Guilford Press.

15. Theofilidis Antonis (2020).Memory Storage Difficulties from Partial Brain Damage. Frontiers in Medical Case Reports.September 2020 | Volume 01| Issue 05 | Page 1- 10

16. Theofilidis Antonis (2020).Cognitive Deficits in a Patient with Post-Traumatic Epilepsy. Clinical Cases in Medicine.2020 | Volume 1 | 
This work is licensed under Creative Commons Attribution 4.0 License

To Submit Your Article Click Here: Submit Manuscript

DOI: $10.31579 / 2578-8868 / 185$
Ready to submit your research? Choose Auctores and benefit from:

* fast, convenient online submission

* rigorous peer review by experienced research in your field

* rapid publication on acceptance

* authors retain copyrights

* unique DOI for all articles

* immediate, unrestricted online access

At Auctores, research is always in progress.

Learn more www.auctoresonline.org/journals/neuroscience-andneurological-surgery 